\title{
Seronegative dengue cases in children - a retrospective analysis in a tertiary care center in Puducherry
}

\author{
Maheswari K. ${ }^{1}$, Savitha B. ${ }^{2}$, Sharma N. ${ }^{3 *}$ \\ DOI: https://doi.org/10.17511/ijpr.2020.i04.01 \\ 1 Maheswari K., Associate Professor, Department of Paediatrics, Sri Venkateshwaraa Medical College Hospital and Research Centre, \\ Puducherry, India. \\ 2 Savitha B., Assistant Professor, Department of Microbiology, Sri Venkateshwaraa Medical College Hospital and Research Centre, \\ Puducherry, India. \\ 3* Neha Sharma, Assistant Professor, Department of Paediatrics, Sri Venkateshwaraa Medical College Hospital and Research Centre, \\ Puducherry, India.
}

Objectives: This study was undertaken to know the clinical profile and outcome of seronegative dengue cases in children, admitted to a tertiary care teaching hospital in Puducherry. Materials and methods: This is a hospital-based, retrospective, descriptive study, done on seronegative dengue cases, of children aged 1 to 15 years of age, admitted and treated in the pediatric department and pediatric intensive care unit from June 2017 - December 2019, in Sri Venkateshwaraa Medical College and Research Centre, Puducherry. Results: About 75 children were suspected of dengue fever during the study period and those blood samples were sent for dengue serology. Only 16 cases $(21.3 \%)$ were reported to be dengue serology positive. The remaining $59(78.6 \%)$ were dengue serology negative. A total of about 33 children who fulfilled the inclusion criteria were studied and the results were analyzed. It was seen that, male children outnumbered (69.6\%), females (30.3\%). Maximum numbers of cases were seen among $11-15$ years of age $(51.5 \%)$, followed by (36.3\%) in 6 to 10 years of age and (12.1\%) in 1-5 years of age. Conclusion: The current study has revealed that seronegative dengue cases are more common than seropositive cases in children. They present with common symptoms and rarely atypical symptoms. Clinical diagnosis is more important because of the increasing trend of seronegative dengue cases in children, either because of late or atypical presentation and since the burden of dengue is being underestimated. A high index of clinical suspicion is needed, in spite of seronegativity in children with dengue, in order to reduce the morbidity and improve the outcome in epidemics as well as in daily clinical practice.

Keywords: Seronegative dengue fever, Clinical features, Outcome

Corresponding Author

Neha Sharma, Assistant Professor, Department of Paediatrics, Sri Venkateshwaraa Medical College Hospital and Research Centre, Puducherry, India. Email: nehu.sharma8785@gmail.com

\section{How to Cite this Article}

Maheswari K, Savitha B, Sharma N. Seronegative dengue cases in children - a retrospective analysis in a tertiary care center in Puducherry. Pediatric Rev Int J Pediatr Res. 2020;7(4):160-165.

Available From

https://pediatrics.medresearch.in/index.php/ijpr/arti cle/view/595
To Browse

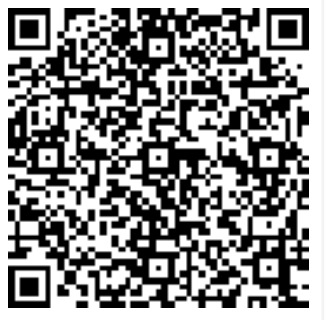

Manuscript Received 2020-04-06

Conflict of Interest No

(c) 2020 by Maheswari K., Savitha B., Neha Sharma and Published by Siddharth Health Research and Social Welfare Society. This is an Open Access article licensed under a Creative Commons Attribution 4.0 International License https://creativecommons.org/licenses/by/4.0/ unported [CC BY 4.0].

Accepted 2020-04-28

Review Round 1 2020-04-17

Funding

2020-04-23

Note 


\section{Introduction}

Dengue is the most rapidly spreading mosquitoborne viral disease in the world. in the last 50 years, the incidence has increased 30-fold with increasing geographical expansion to new countries and in the present decade, from urban to rural settings. More than $70 \%$ of the population at risk for dengue worldwide, live in member states of the WHO South East Asia Region and West Pacific Region which bear nearly $75 \%$ of the current global disease burden due to dengue [1]. The relationship of this country with dengue has been long and intense. After the first virologically proved epidemic of dengue fever along the east coast of India in 1963-1964, it spread all over the country [2]. There are currently no vaccines nor antiviral drugs available for dengue virus; the only effective way to prevent epidemic DF/DHF is to control the mosquito vector, Aedes aegypti [3]. Dengue remains a puzzling disease in many aspects, such as the virus -vector and host-virus relationship, and clinical expression variability [4]. WHO has given the case definition of dengue fever in its comprehensive guidelines. Accordingly, a probable cause is defined as an acute febrile illness with two or more of any findings viz. headache, retro-orbital pain, myalgia, arthralgia, rash, hemorrhagic manifestations, leucopenia and supportive serology [5]. Dengue hemorrhagic fever (DHF) is characterized by fever; hemorrhagic manifestations; thrombocytopenia; increased capillary permeability; pleural effusion or hypoalbuminemia. Dengue shock syndrome (DSS) shows features of DHF with hypotension [6]. In 2009, the WHO proposed a new classification, dengue, and serious dengue, in which dengue is subdivided according to the presence or absence of the following warning signs: abdominal pain, persistent vomiting, edema, mucosal bleeding, lethargy, irritability, hepatomegaly $(>2 \mathrm{~cm})$, and increased hematocrit concurrent with decreased platelet count[7]. Early diagnosis of dengue virus infection is important for treatment and aversion of complications like DSS and DHF. Dengue virusspecific IgM antibodies appear as early as three days of dengue viral fever and can persist for 30-60 days, whereas IgG antibodies appear at about seventh day, peak at 2-3 weeks, and persist for life [8]. Dengue fever is not easily diagnosed before the presentation of the classic symptoms. Combinations of the symptoms and dynamic ordinary laboratory tests are helpful to physicians for accurate diagnosis of dengue fever [9].
This study was undertaken to emphasize the importance of clinical diagnosis of dengue fever because of the increasing trend of seronegative dengue cases in children, either because of late or atypical presentation and since the burden of dengue is being underestimated.

\section{Materials and Methods}

This is a hospital-based, retrospective, descriptive study of seronegative dengue cases, of children aged 1 to 15 years of age, admitted and treated in the pediatric department and pediatric intensive care unit from June 2017 - December 2019, in Sri Venkateshwaraa Medical College and Research Centre, Puducherry. The patients needed for this study were identified by reviewing, the nominal register in the pediatric department and pediatric intensive care unit by the diagnosis of dengue fever. Patient information was collected from the medical records department and dengue serology register in the microbiology department.

\section{Inclusion criteria:}

- 1 to 15 years old children admitted with probable dengue illness (Seronegative with fever and thrombocytopenia and increased hematocrit with suggestive symptoms and warning signs of dengue fever).

- Complete patient information along with clinical profile, hematological, serological, and ultrasonography reports in the medical records.

\section{Exclusion criteria:}

- Children with incomplete medical records

- Fever due to other confirmed causes

- Seropositive cases of dengue.

The following data was collected from the medical records department (MRD) about the children included in this study.

*Age, gender, clinical profile, and management and outcome of these patients.

*Total leucocyte count, platelet count, hemoglobin levels, hematocrit, peripheral smear, chest $\mathrm{x}$-ray, LFT, RFT, blood coagulation profile, ultrasonography findings of the abdomen was noted.

\section{Results}

During the study period of June 2017-December 2019, 75 children were suspected of dengue fever and the blood samples sent for dengue serology 
Showed that only 16 cases $(21.3 \%)$ were reported to be dengue serology positive. The remaining 59 (78.6\%) were dengue serology negative. A total of about 33 children that fulfilled the inclusion criteria were studied and the results were analyzed as given below.

\section{Table-1: Distribution of children according to} gender.

\begin{tabular}{|l|l|}
\hline \multicolumn{1}{|c|}{ Demographic data } & \multicolumn{1}{c|}{ No $(\%)(\mathrm{N}=33)$} \\
\hline Male & $23(69.6)$ \\
\hline Female & $10(30.3)$ \\
\hline
\end{tabular}

In Table-1, it was seen that out 33 cases studied, male children 23 ( 69.6\%), female 10 (30.3\%).

Table 2: Distribution of children according to age group.

\begin{tabular}{|l|l|l|l|l|}
\hline Age & \multicolumn{1}{|c|}{$\begin{array}{c}\text { DF (with-out } \\
\text { warning signs) }\end{array}$} & $\begin{array}{l}\text { DF with warning } \\
\text { signs }\end{array}$ & $\begin{array}{c}\text { Severe } \\
\text { dengue }\end{array}$ & $\begin{array}{c}\text { Total No } \\
(\%)\end{array}$ \\
\hline $\begin{array}{l}1-5 \\
\text { years }\end{array}$ & 4 & Nil & Nil & $4(12.1)$ \\
\hline $\begin{array}{l}6-10 \\
\text { years }\end{array}$ & 5 & 7 & Nil & $12(36.3)$ \\
\hline $\begin{array}{l}11-15 \\
\text { years }\end{array}$ & 12 & 4 & 1 & $17(51.5)$ \\
\hline
\end{tabular}

Table 2 shows that the maximum numbers of seronegative dengue cases were seen among 11-15 years of age cases $17(51.5 \%)$, followed by 12 cases $(36.3 \%)$ in 6 to 10 years of age and 4 $(12.1 \%)$ in $1-5$ years of age.

Table 3: Distribution of children according to clinical profile.

\begin{tabular}{|l|l|}
\hline \multicolumn{1}{|c|}{ Clinical profile } & \multicolumn{1}{|l|}{ Frequency / percentage } \\
\hline Symptom & \multicolumn{1}{|l|}{$33(100)$} \\
\hline Fever & $27(81.8)$ \\
\hline Anorexia & $21(63.6)$ \\
\hline Generalized myalgia & $14(42.4)$ \\
\hline Headache & $10(30.3)$ \\
\hline Pain abdomen & $6(18.1)$ \\
\hline Vomiting & $5(15.1)$ \\
\hline Loose stools & $3(9)$ \\
\hline Cough/cold & $2(6)$ \\
\hline Rashes & \multicolumn{2}{|l|}{} \\
\hline Signs & $30(90.9)$ \\
\hline Hepatomegaly & $12(36.3)$ \\
\hline Splenomegaly & $9(27.2)$ \\
\hline Pedal-edema & $5(15.1)$ \\
\hline Pleural effusion & $4(12.1)$ \\
\hline Ascites & $1(3)$ \\
\hline Hypotension & $1(3)$ \\
\hline Altered sensorium &
\end{tabular}

Bleeding $1(3)$

It was seen that according to Table 3, the most common symptom seen in seronegative dengue cases was fever seen in $33(100 \%)$ of cases, followed by anorexia 27cases ( $81.8 \%)$, generalized myalgia 21 cases $(63.6 \%)$, headache 14 cases $(42.4 \%)$, pain abdomen in 10 cases( $30.3 \%)$, vomiting 63 cases $(18.1 \%)$, loose stools 5 cases $(15.1 \%)$, cough 3 cases $(9 \%)$, rashes in 2 case $(6 \%)$.

The most common sign was hepatomegaly 30 cases (90.9\%), splenomegaly 12 cases $(36.3 \%)$, pedal edema 9 (27.2\%), pleural effusion 5 (15.1\%), ascites $4(12.1 \%)$ and hypotension, altered sensorium and bleeding in 1 case (3\%).

Table 4: Distribution according to hospital stay and outcome of the patients

\begin{tabular}{|l|l|l|l|l|}
\hline $\begin{array}{c}\text { Hospital stay } \\
\text { and Outcome }\end{array}$ & $\begin{array}{c}\text { DF without } \\
\text { warning signs }\end{array}$ & $\begin{array}{c}\text { DF with } \\
\text { warning signs }\end{array}$ & $\begin{array}{c}\text { Severe } \\
\text { dengue }\end{array}$ & $\begin{array}{c}\text { Total No } \\
(\%)\end{array}$ \\
\hline Less than 5 days & 19 & 2 & Nil & $21(63.6)$ \\
\hline $6-10$ days & 2 & 9 & 1 & $12(36.3)$ \\
\hline Discharged & 21 & 7 & Nil & $28(84.8)$ \\
\hline AMA & Nil & 4 & Nil & $4(2.1)$ \\
\hline $\begin{array}{l}\text { Discharged at } \\
\text { request }\end{array}$ & Nil & Nil & 1 & $1(3.0)$ \\
\hline
\end{tabular}

According to Table 4, it was seen that 21 (63.6\%) of patients were discharged in $<5$ days. Most of them belong to DF without warning signs. About 12 (36.3\%) were discharged after 5 days of admission, most of them had warning signs. According to the outcome it was seen that 28 (84.8\%), were discharged, $4(2.1 \%)$ went against medical advice and $1(3 \%)$ case of severe dengue was discharged at request.

\section{Discussion}

The involvement of younger age groups and an increase in the frequency of epidemics are indicators of higher incidence of infection [10]. Ninety percentage of DHF subjects are children less than 15 years of age [11]. Without proper treatment the case fatality rate in severe dengue is more than $20 \%$ and with timely intervention, it can be reduced to $1 \%$ [12].

During the study period, 75 children were suspected of dengue fever and the blood samples were sent for dengue serology. Only 16 cases (21.3\%) were reported to be dengue serology positive. The remaining $59(78.6 \%)$ were dengue serology negative. 
Which showed that serology negative outnumbered serology positive cases. In a study done by Ho-Chen et al, it was seen that out of 317 pediatric cases clinically suspected of dengue, 205 were serology positive and 112 were serology negative [9].

A total of about 33 children that fulfilled the inclusion criteria were studied and the results were analyzed. In the present study, it was seen that, there was a preponderance of male children 23 ( $69.6 \%)$, than females 10 (30.3\%). Maximum numbers of cases were seen among 11-15 years of age cases $17(\%)$, followed by 12 cases (36.3\%) in 6 to 10 years of age and $4(12.1 \%)$ in 1 - 5 years of age. Similar findings were also observed in a study conducted by Ho-Chen et al in seronegative dengue fever in children as well as in studies done in Malaysia and Pondicherry $[9,13,14]$.

The most common symptom was fever seen in 33 $(100 \%)$ of cases, followed by anorexia 27cases $(81.8 \%)$, generalised myalgia 21 cases (63.6\%), headache 14 cases $(42.4 \%)$, pain abdomen in 10 cases( $30.3 \%)$, vomiting 6 cases $(18.1 \%)$, loose stools 5 cases $(15.1 \%)$, cough 3 cases $(9 \%)$,rashes in 2 case $(6 \%)$. Similarly, fever was the most common symptom noted in a study conducted in Mumbai during the dengue epidemic [15]. But in a study done by Ho-Chen et al, in seronegative dengue cases, it was seen that cough was the most common clinical symptom [9]. In the current study, the most common atypical findings noted were loose stools and cough. But a study done in Puducherry, lymphadenopathy was the most common atypical finding observed [16].

The most common sign was hepatomegaly 30 cases $(90.9 \%)$, splenomegaly 12 cases $(36.3 \%)$, pedal edema 9 (27.2\%), pleural effusion 5 (15.1\%), ascites $4(12.1 \%)$ and hypotension, altered sensorium and bleeding in 1 case (3\%). Similar findings were seen in a study conducted in Delhi, hepatomegaly being the most common sign [17]. Altered sensorium was noted in (3\%) of cases in the current study in severe dengue patients, which is a well-recognized symptom of dengue encephalitis/increased dengue viral neurotropism [18].

It was seen that $21(63.6 \%)$ of patients were discharged in $<5$ days. Most of them belong to DF without warning signs. About 12 (36.3\%) were discharged after 5 days of admission, most of them had DF with warning signs. In a study done by Mittal et al, the mean duration of hospital stay was
4.2 days [19]. According to the outcome it was seen that $28(84.8 \%)$, were discharged, 4 (2.1\%) went against medical advice and 1 (3\%) case of severe dengue was discharged at request. A similar outcome was observed in a study done in Odisha [20].

\section{Conclusion}

The current study has revealed that seronegative dengue cases are more common than seropositive dengue cases in children. They present with common symptoms and rarely atypical symptoms.

\section{What does the study add to the existing knowledge?}

Clinical diagnosis is more important than dependence on positive serology because of the increasing trend of seronegative dengue cases in children, either because of late or atypical presentation and since the burden of dengue is being neglected and underestimated. A high index of suspicion is needed, in spite of seronegativity in children with dengue in order to reduce the morbidity and improve the outcome in epidemics as well as in daily clinical practice.

\section{Author's contribution}

Dr. Maheswari K.: Study design and data collection from serology register in the microbiology laboratory and MRD.

\section{Dr. Savitha B.: Manuscript analysis}

Dr. Neha Sharma: Data analysis and interpretation of results.

\section{Acknowledgments}

The authors would like to thank all the microbiology laboratory and MRD staff, for helping in the collection of patient information.

\section{Abbreviation}

WHO- World Health Organization

DF- Dengue fever

DHF- Dengue Hemorrhagic Fever

DSS- Dengue Shock Syndrome

MRD- Medical Records Department

LFT- Liver Function Test 
RFT- Renal Function Test

AMA-Against Medical Advice

\section{Reference}

01. World Health Organization. Dengue guidelines for diagnosis, treatment, prevention and control- new edition. World Health Organization. 2009. Available at

[Article] [Crossref]

02. Chaturvedi UC, Nagar R. Dengue and dengue haemorrhagic fever- Indian perspective. J Biosci. 2008;33(4)429-441.

doi: $\quad 10.1007 / \mathrm{s} 12038-008-0062-3 \quad$ [Crossref]

03. Gubler DJ. Dengue/dengue haemorragic feverhistory and current status. Novartis Found Symp. 2006;277;3-16.

doi: $10.1002 / 0470058005 . c h 2$ [Crossref]

04. Ratageri VH, Wari SP, Chavan SC, Mujahid IB, Yergolkar PN. Clinical Profile and Outcome of Dengue Fever Cases. Indian J Pediatr. 2005;72(8)705-706.

doi: $10.1007 / \mathrm{bf02724083 \quad \text {[Crossref] }}$

05. Kadam DB, Salvi S, Chandanwale A. Expanded Dengue. J Assoc Physicians India. 2016;64(7)59-63.

[Crossref]

06. Chacko B, Subramanian G. Clinical, Laboratory and Radiological Parameters in Children with Dengue Fever and Predictive Factors for Dengue Shock Syndrome. J Trop Pediatr. 2007;54(2)265-270.

doi: 10.1093/tropej/fmm084 [Crossref]

07. Pone SM, Hokerberg YH, de Oliveira RV, Daumas RP, Pone TM, Pone MV, et al. Clinical and laboratory signs associated with serious dengue disease in hospitalized children. J Pediatr (Rio J). $2016 ; 92(5) 464-471$.

doi: $10.1016 /$ j.jped.2015.12.005 [Crossref]

08. Padhi S, Dash M, Panda P, Parida B, Mohanty I, Sahu $S$, et al. A three-year retrospective study on the increasing trend in seroprevalence of dengue infection from southern Odisha, India. Indian J Med Res. 2014;140(5)660-664.

[Crossref]
09. Chen Li C, Ho Chen C. Clinical features and dynamic ordinary laboratory tests differentiating dengue fever from other febrile illnesses in children. J Microbiol, Immunol Infect. 2018;51(5)614-620.

doi: 10.1016/j.jmii.2016.08.018 [Crossref]

10. Narayanan $M$, Aravind $N$, Thilothammal $R$, Prema R, Sargunam CS, Ramamurty N. Dengue Fever Epidemic in Chennai-A Study of Clinical profile and Outcome. Indian Pediatr. 2002;39(11)1027-1033.

[Crossref]

11. Malavige GN, Fernando S, Fernando DJ, Seneviratne SL. Dengue viral infections. Postgrad Med J. 2004;80(948)588-601. doi: $10.1136 / p g m j .2004 .019638$ [Crossref]

12. Pothapregada S, Kamalakannan B, Thulasingham M, Sampath S. Clinical Profiling Pediatric Patients with Dengue. J Glob Infect Dis. 2016:8(3)115-120. doi: $10.4103 / 0974-777 x .188596$ [Crossref]

13. Mallhi TH, Khan AH, Adnan AS, Sarriff A, Khan $\mathrm{YH}$, Jummaat F. Clinicolaboratory spectrum of dengue viral infection and risk feactors associated with dengue hemorrhagic fever :a retrospective study. BMC Infect Dis. $2015 ; 15 ; 399$.

doi: 10.1186/s12879-015-1141-3 [Crossref]

14. Pothapregada S, Kamalakannan B, Thulasingam M. Risk factors for shock in children with dengue fever. Indian J Crit Med. 2015;19(11)661-664. doi: $10.4103 / 0972-5229.169340$ [Crossref]

15. Shah I, Deshpande GC, Tardeja PN. Outbreak of dengue in Mumbai and predictive markers for dengue shock syndrome. J Trop Pediatr. 2004;50(5)301-305.

doi: 10.1093/tropej/50.5.301 [Crossref]

16. Propregada S, Kamalakannan B, Thulasingam M. Clinical profile of atypical manifestations of dengue fever. Indian J Pediatr. 2016;83(6)493499.

doi: $\quad 10.1007 / s 12098-015-1942-9 \quad$ [Crossref] 
17. Aggarwal A, Chandra J, Aneja S, Patwari AK, Dutta AK. An epidemic of dengue hemorrhagic fever and dengue shock syndrome in children in Delhi. Indian Pediatr. 1998;35(8)727-732.

[Crossref]

18. Varatharaj A. Encephalitis in the clinical spectrum of dengue infection. Neurol India. 2010;58(4)585-591.

doi: $10.4103 / 0028-3886.68655$ [Crossref]
19. Mittal H, Faridi MMA, Arora SK, Patil R. Clinico hematological Profile and Platelet trends in Children with Dengue During 2010 Epidemic in North India. Indian J Pediatr. 2012;79(4)467471.

doi: 10.1007/s12098-011-0586-7 [Crossref]

20. Mishra S, Ramanathan R, Agarwalla SK. Clinical Profile of Dengue Fever in Children- A Study from Southern Odisha, India. Scientifica. $2016 ; 6391594$.

doi: $\quad 10.1155 \% 2 F 2016 \% 2 F 6391594 \quad$ [Crossref] 